\title{
Electron transfer in $N$-butylpyridinium tetrafluoroborate ionic liquid by pulse radiolysis
}

\author{
FU HaiYing $^{1 *}$, XING ZhaoGuo $^{2}$, CAO XiYan ${ }^{2} \&$ WU GuoZhong ${ }^{1}$ \\ ${ }^{1}$ Laboratory of Radiation Chemistry, Shanghai Institute of Applied Physics, Chinese Academy of Sciences, Shanghai 201800, China; \\ ${ }^{2}$ Hunan University of Science and Technology, Xiangtan 411201, China
}

Received October 7, 2012; accepted November 6, 2012; published online January 28, 2013

\begin{abstract}
The radiolysis behavior of neat pyridinium ionic liquids (ILs) and their aqueous solutions was investigated using nanosecond pulse radiolysis techniques. Radiolysis of the ionic liquids, such as $N$-butylpyridinium tetrafluoroborate $\left(\mathrm{BuPyBF}_{4}\right)$, resulted in the formation of solvated electrons and organic radicals. Solvated electrons reacted with the pyridinium moiety to produce a pyridinyl radical, which can transfer electrons to various acceptors. The electron-transfer rate constants of the solvent-derived butylpyridinyl radicals in $\mathrm{BuPyBF}_{4}$ and in several compounds (for example, duroquinone, 4,4'-pyridine, benzophenone, and 1,1'dimethyl-4,4'-bypyridinium dichloride) ( $k$ of the order $10^{8} \mathrm{~L} /(\mathrm{mol} \mathrm{s}$ ) were lower than those measured in water and in $i$-PrOH but were significantly higher than the diffusion-controlled rate constants estimated based on viscosity. The electron-transfer rate constants in neat $\mathrm{BuPyBF}_{4}$ were one order of magnitude faster than the diffusion-controlled values. This finding suggests that $\mathrm{Bu}-$ $\mathrm{PyBF}_{4}$ acts not only as solvent but also as active solute, such as in solvent-mediated reactions. These reactions result in electrons reaching their final destinations via intervening pyridinium groups without requiring the diffusion of a specific radical.
\end{abstract}

pulse radiolysis, ionic liquid, transient absorption, electron transfer

Citation: $\quad$ Fu H Y, Xing Z G, Cao X Y, et al. Electron transfer in $N$-butylpyridinium tetrafluoroborate ionic liquid by pulse radiolysis. Chin Sci Bull, 2013, 58: 1882-1886, doi: 10.1007/s11434-013-5684-7

In recent years, ionic liquids (ILs) have become the most studied class of solvents and are considered valid potential substitutes of many volatile organic solvents [1-3]. ILs are salts and thus are ionic compounds in liquid form at or near room temperature. ILs exhibit several unique thermophysical properties owing to their asymmetrical structures and the charge dispersion of their organic and inorganic ions. These compounds do not evaporate at ambient temperature and have relatively high thermal stability, high ionic conductivity, and large liquid temperature range. ILs also demonstrate excellent solvent quality for many types of compounds. Traditional methods of chemical kinetics must be applied to the study of IL chemical reactivity to exploit properly the potential of these solvents.

In this work, pulse radiolysis techniques were used to observe the electron-transfer reactivity of $N$-butylpyridin-

\footnotetext{
*Corresponding author (email: fuhaiying@ sinap.ac.cn)
}

ium tetrafluoroborate $\left(\mathrm{BuPyBF}_{4}\right)$ ILs with several transient species. Pulse radiolysis is a technique where samples are irradiated using a laser-generated beam of high-energy electrons and the species (electron, radicals, cations, etc.) are studied through their absorption spectra [4]. This technique is useful for studying reaction rates, particularly for very fast reactions such as redox reactions and reactions that contain short-lived species. Neta and co-workers [5,6] compared the reaction rate constants of ILs with those of traditional solvents (acetonitrile and alcohol) to determine the stability of ILs as alternative reaction solvents for specific reactions. They studied reaction kinetics in imidazolium salts and in methyltributylammonium bis (trifluoromethylsulfonyl)imide [7-9]. However, to the best of our knowledge, only a few studies focused on the kinetic reactivity of pyridinium-based ILs. In the current study, we extend our earlier investigations to consider the effects of the size and shape of solute ions that undergo transient reac- 
tions [10]. We also selected several chemical probes, such as 9,10-anthraquinone-2-sulfonate (AQS), duroquinone (DQ), and benzophenone (BP), as models to observe the electron-transfer processes between the probes and $\mathrm{Bu}$ $\mathrm{PyBF}_{4}$. We present a comparative study of electron transfer between probes in ILs and other solvents. Related rate constants are obtained, and possible mechanisms are proposed in this study.

\section{Experimental}

\subsection{Materials}

Ionic liquid $\mathrm{BuPyBF}_{4}$ (Shyfhx Corp.) was treated with activated charcoal for at least $48 \mathrm{~h}$ and then filtered twice by passing through a Celite column. The IL was transferred into a clean, dry reagent bottle and kept under vacuum for $12 \mathrm{~h}$ at $65^{\circ} \mathrm{C}$ to remove any volatile organic impurities and moisture. The purified IL was stored in an airproof desiccator. Various compounds were used to probe reduction and oxidation reactions. The probes AQS, DQ, 4,4'-pyridine (BPY), BP, and 1,1'-dimethyl-4,4'-bypyridinium dichloride $\left(\mathrm{MV}^{2+}\right)$ were purchased from Sigma and used as received. All other reagents were of purest grade. Unless otherwise indicated, all solutions were freshly prepared with Millipore filtered water (Milli-Q, Element A-10) before each experiment. Sample solutions were bubbled with high-purity argon, nitrous oxide, or oxygen for each purpose for over 20 min prior to radiation. All experiments were carried out at $(22 \pm 2)^{\circ} \mathrm{C}$.

\subsection{Methods}

Pulse radiolysis experiments were performed using $10 \mathrm{MeV}$ electrons obtained from a linear electron accelerator for in situ generation with 20 ns duration in the Shanghai Institute of Applied Physics, China. Detailed descriptions of the setup of pulse radiolysis equipment and experimental conditions are described in ref. [11]. The absorbed dose was measured using an $\mathrm{N}_{2} \mathrm{O}$-saturated $100 \mathrm{mmol} / \mathrm{L} \mathrm{KSCN}$ aqueous solution $(G \times \varepsilon=51000 \mathrm{~J} / \mathrm{cm}$ at $472 \mathrm{~nm})$ [12]. The absorbed dose was $\sim 15 \mathrm{~Gy} /$ pulse. The source of analyzing light was a $500 \mathrm{~W}$ xenon lamp. The kinetic spectrophotometric detection system covered a wavelength ranging from 250 to $800 \mathrm{~nm}$, and the light length of the quartz cell was $1.0 \mathrm{~cm}$. Rate constants and molar absorption coefficients were reported with their estimated standard uncertainties.

Radiolysis of liquid results in the production of solvated electrons and solvent radical cations. Solvated electrons may react with solvents. However, when this reaction is slow, the solvated electrons may react with solutes instead. Radical cations may oxidize solutes or may undergo deprotonation or fragmentation, and the products then react with solutes differently. Geminate recombination of solvated electrons and radical cations produces excited species, which may undergo fragmentation to form radicals. Despite this complexity, clean reduction or oxidation reactions in many solvents is possible because of the rapid conversion of primary species and selective reactions. Some mechanisms may be predicted based on reaction rates in other solvents.

The pulse radiolysis of water produces highly reactive species, as shown in reaction 1 :

$$
\mathrm{H}_{2} \mathrm{O} M{ }^{\circ} \mathrm{OH}, \mathrm{e}_{\mathrm{aq}}^{-},{ }^{\circ} \mathrm{H}, \mathrm{H}_{2} \mathrm{O}_{2}, \mathrm{HO}_{2}, \cdots
$$

When the sample solution is saturated with $\mathrm{N}_{2} \mathrm{O}$ for 20 min prior to pulse radiolysis, $\mathrm{e}_{\mathrm{aq}}^{-}$is scavenged to form ${ }^{\circ} \mathrm{OH}$ radical (reaction 2).

$$
\mathrm{e}_{\mathrm{aq}}^{-}+\mathrm{N}_{2} \mathrm{O}+\mathrm{H}_{2} \mathrm{O} \rightarrow{ }^{\circ} \mathrm{OH}+\mathrm{OH}^{-}+\mathrm{N}_{2}
$$

To observe the reaction of the substrate with $\mathrm{e}_{\mathrm{aq}}^{-}$, scavenging ${ }^{\circ} \mathrm{OH}$ radicals using tert-butyl alcohols (0.1 to 1 $\mathrm{mol} / \mathrm{L}$ ) in the $\mathrm{N}_{2}$-saturated aqueous solutions is necessary (reaction 3).

$$
\cdot \mathrm{OH}+\left(\mathrm{CH}_{3}\right)_{3} \mathrm{COH} \rightarrow \mathrm{H}_{2} \mathrm{O}+{ }^{\circ} \mathrm{CH}_{2}\left(\mathrm{CH}_{3}\right)_{2} \mathrm{COH}
$$

The viscosities of the tested ionic liquids were determined experimentally using a Rheometric Scientific, Inc. ARES rheometer from TA Instruments. A steady shear rheology test was conducted at $20^{\circ} \mathrm{C}$ using a cone geometry 34 $\mathrm{mm}$ in diameter. Tests were performed at shear rates ranging from 0.1 to $100 \mathrm{~s}^{-1}$ (referenced to the outer radius of the plates); none of the fluids tested showed any sign of non-Newtonian behavior. The relative standard uncertainty of the mean viscosity was less than $5 \%$.

\section{Results and discussion}

\subsection{Radiolysis of pyridinium ionic liquid aqueous solution}

The transient absorption spectrum was obtained under pulse radiolysis for the aqueous solution containing $\mathrm{BuPyBF}_{4}(0.1$ $\mathrm{mmol} / \mathrm{L})$ and $t$-BuOH $(1.0 \mathrm{~mol} / \mathrm{L})$ deoxygenated by $\mathrm{N}_{2}$ (Figure 1). A strong absorption spectrum appeared in a broad wavelength region ranging from 470 to $740 \mathrm{~nm}$ in a short lifetime. Hydrated electron absorption, which decayed rapidly, was observed around $700 \mathrm{~nm}$ at $100 \mathrm{~ns}$. Other absorption bands appeared around $330 \mathrm{~nm}$ at $2 \mu \mathrm{s}$ after the pulse (Figure 1, inset (b)). However, the solvent electron was scarcely observed in neat $\mathrm{BuPyBF}_{4}$ under our experiment conditions, indicating the rapidness of the reaction.

By varying the concentration of $\mathrm{BuPyBF}_{4} \mathrm{IL}$ from 0.01 to $0.4 \mathrm{mmol} / \mathrm{L}$, the decay follows the pseudo-first-order decay law. The plots of the decay rates as a function of the $\mathrm{Bu}-$ $\mathrm{PyBF}_{4}$ concentration show a linear line. The rate constant of the solvated electron reacting with $\mathrm{BuPyBF}_{4}$ was estimated to be $(1.7 \pm 0.1) \times 10^{10} \mathrm{~L} /(\mathrm{mol} \mathrm{s})$ based on the plotted slope of the pseudo-first-order rate versus the initial concentrations of $\mathrm{BuPyBF}_{4}$ (Figure 1, inset (c)).

The $\mathrm{BF}_{4}^{-}$or $\mathrm{PF}_{6}^{-}$anions of the ILs were not active and 


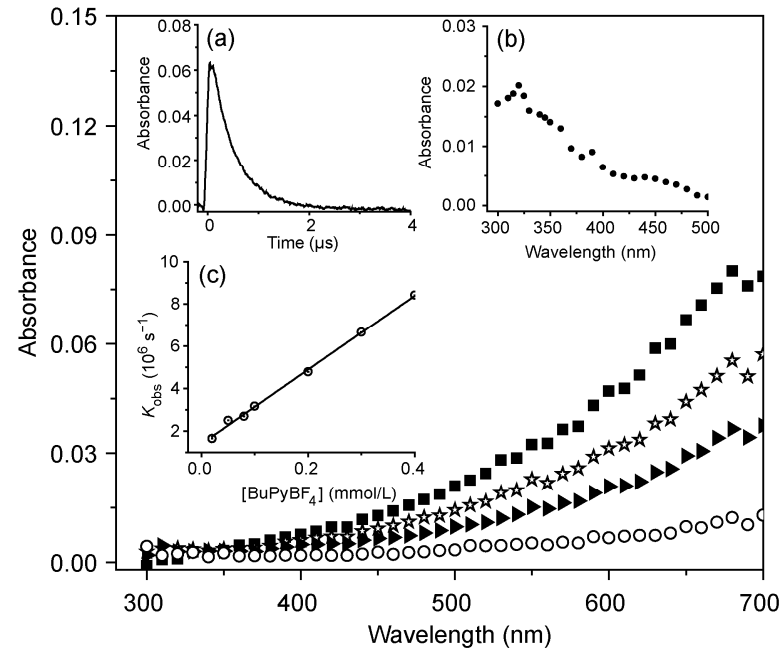

Figure 1 Transient absorption spectra of $0.1 \mathrm{mmol} / \mathrm{L} \mathrm{BuPy} \mathrm{BF}_{4}$ aqueous solution containing $1.0 \mathrm{~mol} / \mathrm{L} t-\mathrm{BuOH}$, saturated with $\mathrm{N}_{2}$, and recorded at (-) 0.1 , (光) $0.3,(\boldsymbol{\Delta}) 0.5$, and (O) $1.0 \mu$ s after the pulse. Inset: (a) kinetics at $640 \mathrm{~nm}$; (b) transient absorption spectra of $0.1 \mathrm{mmol} / \mathrm{L} \mathrm{BuPyBF}_{4}$ recorded at $2.0 \mu$ s after the pulse; (c) plots of observed kinetics at $640 \mathrm{~nm}$ against $\mathrm{BuPy} \mathrm{BF}_{4}$ concentrations.

did not react with solvated electrons. Therefore, radiolysis of $\mathrm{BuPyBF}_{4}$ was assumed to produce solvated electrons, protons, radical cations, and neutral radicals, such as in reaction 4. Solvated electrons can react rapidly with the pyridinium cation to form the neutral butylpyridinyl radical $(\mathrm{Bu}-$ $\mathrm{Py}^{*}$ ) (reaction 5). The typical absorption band of BuPy was around $330 \mathrm{~nm}$, which is consistent with ref. [5].

The spectrum recorded at $2.0 \mu \mathrm{s}$ of $0.1 \mathrm{mmol} / \mathrm{L} \mathrm{BuPyBF}_{4}$ aqueous solution shows a similar weak peak (Figure 1, inset (b)), which is expected when the main absorbing species is the same pyridinyl radical. This radical is expected to transfer an electron to compounds with higher electron affinity, such as quinones, as demonstrated in the next section.

$$
\begin{gathered}
(\mathrm{BuPy})^{+}\left(\mathrm{BF}_{4}\right)^{-} \rightarrow \mathrm{e}_{\text {solv }}^{-}, \mathrm{H}+,(\mathrm{BuPy})^{\cdot 2+}, \mathrm{BF}_{4} \\
\mathrm{BuPy}^{+}+\mathrm{e}_{\mathrm{aq}}^{-} \rightarrow \mathrm{BuPy}
\end{gathered}
$$

\subsection{Electron transfer between probes and BuPy}

In this section we discuss the electron transfer from $\mathrm{Bu}-$ Py to quinones, the electron transfer between quinones and methyl viologen, and compare the rate constants with values measured in other solvents.

(i) Electron transfer between probes and $\mathrm{BuPyBF}_{4}$ in aqueous solution. According to the measured rate constant of pyridium ionic liquids with hydrated electron, we devised the system containing $0.1 \mathrm{mmol} / \mathrm{L}$ probes (AQS or DQ) and $1.0 \mathrm{mmol} / \mathrm{L} \mathrm{BuPyBF} 4$ aqueous solution. Considering the concentration ratio of ILs and probes, the two reactions occur as reactions 5 and 6 .

$$
\mathrm{AQS}+\mathrm{e}_{\mathrm{aq}}^{-} \rightarrow \mathrm{AQS}^{\cdot-}
$$

An important consideration should be taken for assuring that $\mathrm{e}_{\mathrm{aq}}^{-}$produced by water radiolysis predominantly reacts with $\mathrm{BuPyBF}_{4}$. This reaction can be effectuated by carefully adjusting the initial concentrations of $\mathrm{BuPyBF}_{4}$ and $\mathrm{AQS}$. According to the mechanism of competitive reactions, the reaction probability $(p)$ of $\mathrm{BuPyBF}_{4}$ with ${ }^{\circ} \mathrm{OH}$ can be calculated using the following formula:

$$
p=\frac{k_{1}[\mathrm{BuPy}]}{k_{1}[\mathrm{BuPy}]+k_{2}[\mathrm{AQS}]} .
$$

The rate constants of $\mathrm{BuPyBF}_{4}$ and $\mathrm{AQS}$ toward $\mathrm{e}_{\mathrm{aq}}^{-}$are $1.7 \times 10^{10} \mathrm{~L} /(\mathrm{mol} \mathrm{s})\left(k_{1}\right)$ and $2.2 \times 10^{10} \mathrm{~L} /(\mathrm{mol} \mathrm{s})\left(k_{2}\right)$, respectively [13]. When the systems containing $1.0 \mathrm{mmol} / \mathrm{L}$ $\mathrm{BuPyBF}_{4}$ and $0.1 \mathrm{mmol} / \mathrm{L} \mathrm{AQS}$ are applied, $p$ is assumed to be $88 \%$, which indicates that about $88 \%$ of $\mathrm{e}_{\text {solv }}^{-}$produced will react with $\mathrm{BuPyBF}_{4}$ to form $\mathrm{BuPy}$.

Therefore, the main reducing species in the ILs are the butylpyredinyl radical and the electron-transfer reaction (reaction 7). The transient spectra are shown in Figure 2. The strong absorption bands were around 380 and $510 \mathrm{~nm}$, which are typical for AQS anion radical $\left(\mathrm{AQS}^{\circ-}\right)$ [14]. The rate constant was assumed to be $8.0 \times 10^{9} \mathrm{~L} /(\mathrm{mol} \mathrm{s})$.

$$
\mathrm{BuPy}^{\bullet}+\mathrm{AQS} \rightarrow \mathrm{BuPy}^{+}+\mathrm{AQS}^{\cdot-}
$$

$\mathrm{BuPyBF}_{4}$ was used as solute and solvent to compare further its reactivity in ILs. A similar phenomenon was observed in $\mathrm{BuPyBF}_{4}$ solution containing AQS. The absorption peaks of $\mathrm{AQS}^{\circ-}$ appeared at 380 and $510 \mathrm{~nm}$, and the rate constant was measured to be $1.2 \times 10^{8} \mathrm{~L} /(\mathrm{mol} \mathrm{s})$.

The kinetics of AQS at $380 \mathrm{~nm}$ was compared using different solvents (Figure 3); $\mathrm{AQS}^{{ }^{-}}$was formed in the aqueous solution at $1 \mu$ s and then decayed. $\mathrm{AQS}^{{ }^{-}}$was formed slowly in IL-water mixture solutions or neat ILs. Using the same experiment methods, the other probes DQ, MAQ, and BPY also reacted with $\mathrm{BuPy}^{*}$ in neat ionic liquids or IL aqueous solutions. This finding suggests that the BuPy radical has

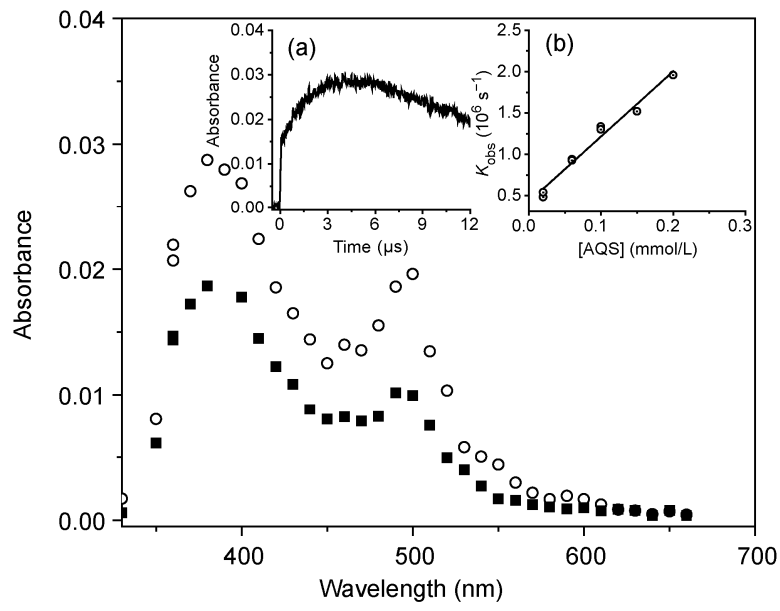

Figure 2 Transient absorption spectra of $1.0 \mathrm{mmol} / \mathrm{L} \mathrm{BuPyBF}_{4}$ aqueous solution containing $0.1 \mathrm{mmol} / \mathrm{L} \mathrm{AQS}$ and $1.0 \mathrm{~mol} / \mathrm{L} t$-BuOH, saturated with $\mathrm{N}_{2}$, and recorded at $(\bullet) 0.5$ and $(0) 5.0 \mu$ s after the pulse. Inset: (a) kinetics at $380 \mathrm{~nm}$; (b) rate constant of 0.02 to $0.22 \mathrm{mmol} / \mathrm{L}$ AQS and 1 $\mathrm{mmol} / \mathrm{L} \mathrm{BuPyBF}_{4}$ aqueous solution. 


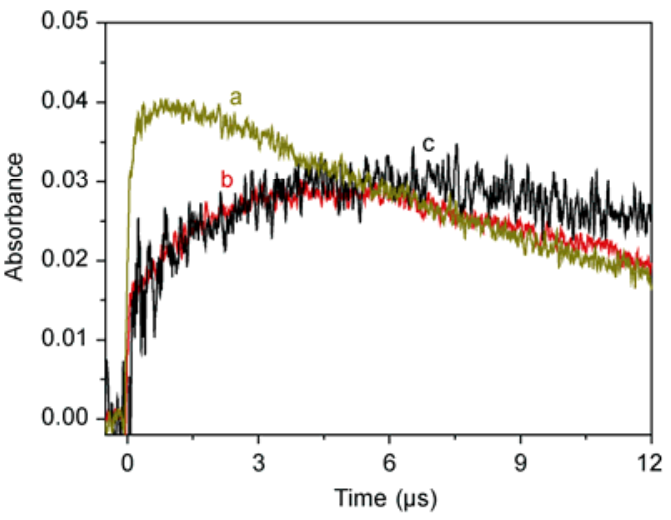

Figure 3 Kinetics of AQS at $380 \mathrm{~nm}$ in various systems. (a) Aqueous solution, (b) $\mathrm{BuPyBF}_{4}$ aqueous solution, and (c) $\mathrm{BuPyBF}_{4}$.

higher reactivity. Table 1 lists the rate constants for different electron-transfer reactions, which will be discussed in subsequent sections of the paper.

(ii) Electron transfer between probes in $\mathrm{BuPyBF}_{4}$. Bu$\mathrm{PyBF}_{4}$ is expected to mediate the electron transfer to the other probe $\mathrm{MV}^{2+}$ because $\mathrm{BuPyBF}_{4}$ is more easily reduced compared with its primary acceptors $\mathrm{BP}$ and BPY. In Bu$\mathrm{PyBF}_{4}$, the reaction of benzophenone with $\mathrm{MV}^{2+}$ first generates the transient spectra of $\mathrm{BuPy}^{\circ}(330 \mathrm{~nm})$ and $\mathrm{BP}^{\circ-}(545$ $\mathrm{nm})$. The addition of $\mathrm{MV}^{2+}$ quenches $\mathrm{BP}^{\bullet}$ and produces $\mathrm{MV}^{+}$ $(610 \mathrm{~nm})$, as shown in Figure 4. The rates and efficiencies for intermolecular electron transfer are monitored by a subsequent reaction of $\mathrm{BP}^{\cdot-}$ with a probe ion $\left(\mathrm{MV}^{2+}\right)$, whose reduced form is detected via its strong absorbance at 610 $\mathrm{nm}$. The favorable reduction reaction of the pyridinium cation permits electron migration via secondary reduction of one or more solvent cations. The reactions are as follows:

$$
\begin{gathered}
\mathrm{BuPy}^{+}+\mathrm{e}_{\text {solv }}^{-} \rightarrow \mathrm{BuPy}^{\bullet} \\
\mathrm{BuPy}^{\cdot}+\mathrm{BP} \rightarrow \mathrm{BP}^{\cdot-}+\mathrm{BuPy}^{+} \\
\mathrm{MV}^{2+}+\mathrm{BP}^{\cdot-} \rightarrow \mathrm{MV}^{\cdot+}+\mathrm{BP}
\end{gathered}
$$

A contrasting behavior was observed in aqueous solution.

\begin{tabular}{|c|c|c|c|}
\hline Reaction & Solvent & $k_{\text {exp }}$ & $k_{\text {diff }}^{\text {a) }}$ \\
\hline $\mathrm{BuPy}^{\bullet}+\mathrm{AQS}$ & $\mathrm{H}_{2} \mathrm{O}$ & $(8.0 \pm 0.5) \times 10^{9}$ & $7.0 \times 10^{9}$ \\
\hline $\mathrm{BuPy}^{*}+\mathrm{AQS}$ & $\mathrm{BuPyBF}_{4}$ & $(1.2 \pm 0.2) \times 10^{8}$ & $4.5 \times 10^{7}$ \\
\hline $\mathrm{BuPy}^{*}+\mathrm{BPY}$ & $\mathrm{H}_{2} \mathrm{O}$ & $(9.8 \pm 0.7) \times 10^{9}$ & $7.0 \times 10^{9}$ \\
\hline $\mathrm{BuPy}^{\bullet}+\mathrm{BPY}$ & $\mathrm{BuPyBF}_{4}$ & $(5.4 \pm 0.4) \times 10^{8}$ & $4.5 \times 10^{7}$ \\
\hline $\mathrm{BuPy}^{*}+\mathrm{MV}^{2+}$ & $\mathrm{H}_{2} \mathrm{O}$ & $(7.7 \pm 0.4) \times 10^{9}$ & $7.0 \times 10^{9}$ \\
\hline $\mathrm{BuPy}^{\circ}+\mathrm{MV}^{2+}$ & $\mathrm{BuPyBF}_{4}$ & $(4.3 \pm 0.2) \times 10^{8}$ & $4.5 \times 10^{7}$ \\
\hline $\mathrm{BuPy}^{\circ}+\mathrm{DQ}$ & $i-\mathrm{PrOH}$ & $(2.0 \pm 0.2) \times 10^{9}$ & $7.0 \times 10^{9}$ \\
\hline $\mathrm{BuPy}^{*}+\mathrm{DQ}$ & $\mathrm{BuPyBF}_{4}$ & $(3.6 \pm 0.2) \times 10^{8}$ & $4.5 \times 10^{7}$ \\
\hline $\mathrm{BuPy}^{\circ}+\mathrm{MAQ}$ & $i-\mathrm{PrOH}$ & $(8.9 \pm 0.5) \times 10^{8}$ & $3.0 \times 10^{9}$ \\
\hline $\mathrm{BuPy}^{\circ}+\mathrm{MAQ}$ & $\mathrm{BuPyBF}_{4}$ & $(1.2 \pm 0.1) \times 10^{8}$ & $4.5 \times 10^{7}$ \\
\hline $\mathrm{MV}^{+}+\mathrm{DQ}$ & $2 \% i-\mathrm{PrOH}-\mathrm{H}_{2} \mathrm{O}$ & $(2.0 \pm 0.2) \times 10^{9}$ & $7.0 \times 10^{9}$ \\
\hline $\mathrm{AQS}+\mathrm{BPY}$ & $4 \% i-\mathrm{PrOH}-\mathrm{H}_{2} \mathrm{O}$ & $(4.6 \pm 0.3) \times 10^{9}$ & $7.0 \times 10^{9}$ \\
\hline $\mathrm{MV}^{2+}+\mathrm{BP}$ & $\mathrm{BuPyBF}_{4}$ & $(8.0 \pm 0.5) \times 10^{8}$ & $4.5 \times 10^{7}$ \\
\hline
\end{tabular}
When the system contained $1.2 \mathrm{mmol} / \mathrm{L} \mathrm{BPY}$ and 0.2

Table 1 Rate constants for different electron-transfer reactions

a) The viscosity of $\mathrm{BuPyBF}_{4}$ at $20^{\circ} \mathrm{C}$ was $0.145 \mathrm{~Pa}$ s.

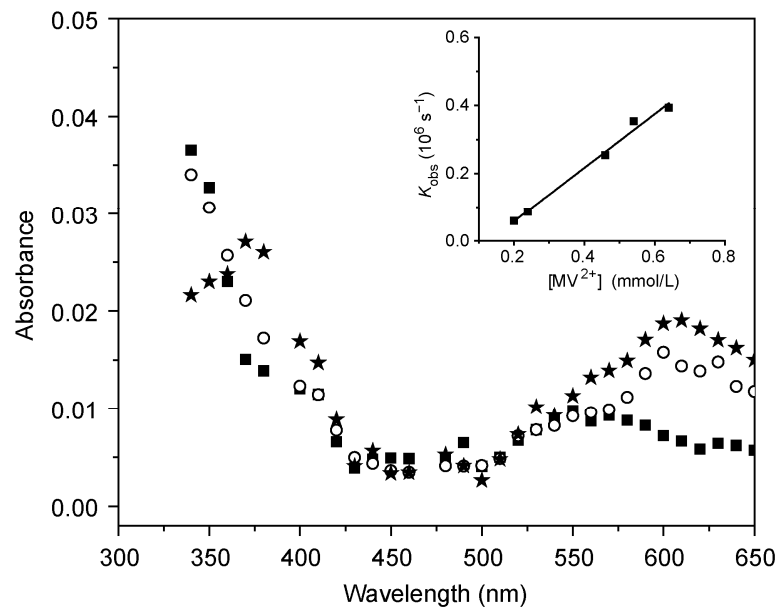

Figure 4 Transient absorption spectra of $1.1 \mathrm{mmol} / \mathrm{L} \mathrm{BP}$ and 0.28 $\mathrm{mmol} / \mathrm{L} \mathrm{MV}^{2+}$ in $\mathrm{BuPyBF}_{4}$, saturated with $\mathrm{N}_{2}$, and recorded at (- 0.5 , (०) 3 , and (*) $15 \mu$ s after the pulse. Inset: plots of observed kinetics at $610 \mathrm{~nm}$ against $\mathrm{MV}^{2+}$ concentrations.

mmol/L AQS in $i$-PrOH $4 \%$ aqueous solution, decay and formation were observed at 580 and $510 \mathrm{~nm}$, respectively, which were almost synchronous to that of Figure 5. Two main absorption bands of BPY were presented at 375 and $580 \mathrm{~nm}$, which were assigned to the 4,4'-BPY radical [15]. The peak at $510 \mathrm{~nm}$ contributed to the $\mathrm{AQS}^{\circ-}$ anion radical. Therefore, the electron transfer between AQS and BPY occurred as reaction (11). The rate constant was measured to be $4.6 \times 10^{9} \mathrm{~L} /(\mathrm{mol} \mathrm{s})$.

$$
\mathrm{AQS}+\mathrm{BPY}^{\bullet} \rightarrow \mathrm{AQS}^{\bullet-}+\mathrm{BPY}^{+}
$$

The electron-transfer reactions occurred in pyridiumbased ionic liquids and other conventional solvents. The rate constants for the same reactions are listed in Table 1. These measured values should be compared with the diffusion-controlled rate constants, which can be estimated using

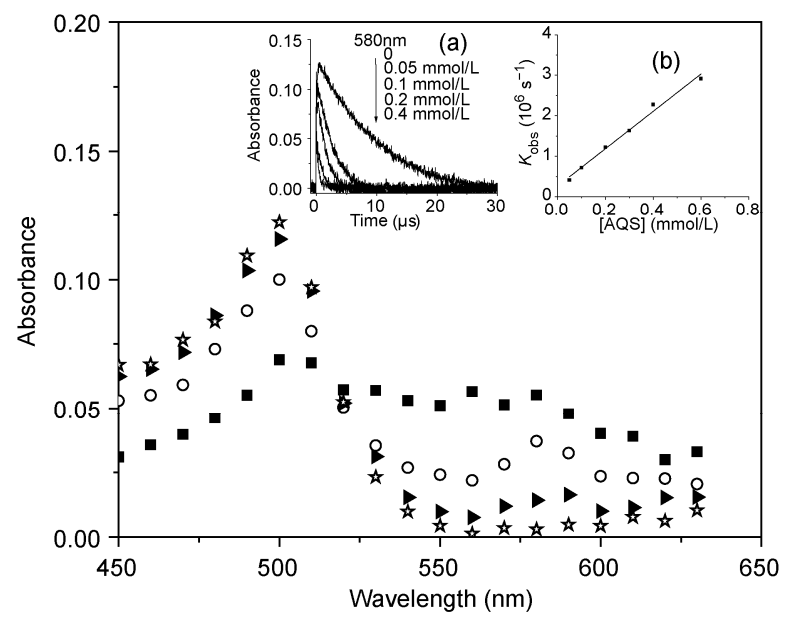

Figure 5 Transient absorption spectra of $1.2 \mathrm{mmol} / \mathrm{L}$ BPY and 0.2 mmol/L AQS aqueous solution containing 4\% i-PrOH, saturated with $\mathrm{N}_{2}$, and recorded at (-) $0.1,(\circ) 0.5,(\bullet) 1.0$, and (ઐ) $2.0 \mu$ s after the pulse. Inset: (a) decay at $580 \mathrm{~nm}$; (b) plots of observed kinetics at $580 \mathrm{~nm}$ against AQS concentrations. 
the viscosities.

The viscosity of the neat ionic liquid $\mathrm{BuPyBF}_{4}$ was 0.145 $\mathrm{Pa} \mathrm{s}$ at room temperature. We can estimate the diffusioncontrolled rate constant $\left(k_{\text {diff }}\right)$ using the above viscosity $[16,17]$. Here, $k_{\text {diff }}=8000 R T / 3 \eta$, where $R$ is the gas constant (8.3144 $\mathrm{J}(\mathrm{K} \mathrm{mol}), T$ is the absolute temperature, and $\eta$ is the viscosity (in Pa s). The values of $k_{\text {diff }}$ for the respective conditions (Table 1) were estimated from the viscosity measured under those conditions (i.e. with solutions containing all the main components and not neat solvents only). The diffusion rates in the neat room temperature ionic liquid (RTIL) were slower than those in RTIL-co-solvent mixtures because of the high viscosity of neat ionic liquids. In all cases, the rate constants were about one order of magnitude higher in water than in the ILs. The rate constant of DQ was also measured in $i$-PrOH and had an intermediate value between water and in the ionic liquid.

The electron-transfer rate constants in water and $i$-PrOH were lower than the values of $k_{\text {diff }}$, which is observed in numerous reactions. Thus, IL only acted as a solute. By contrast, all the rate constants measured in the neat ionic liquids were approximately one order of magnitude higher than the calculated constant $k_{\text {diff. }}$ This finding may be attributed to the electron-transfer mechanism that involves electron hopping between solvent cations, thus permitting the unpaired electron of $\mathrm{BuPy}{ }^{\circ}$ to reach the organic substrate without the need for complete diffusion of a specific BuPy radical to the substrate. Electron transfer is facilitated when a neutral substrate is solvated by pyridinium cations, which can channel electrons.

Moreover, the comparison of electron transfer in $\mathrm{Bu}-$ $\mathrm{PyBF}_{4}$ and water supports the solvent-mediated electrontransfer pathway for $\mathrm{BuPyBF}_{4}$. A solely diffusive electrontransfer pathway is illustrated in BPY and AQS in aqueous solution. The electron-transfer rate constant from $\mathrm{BPY}^{--}$to AQS is approximately $4.6 \times 10^{9} \mathrm{~L} /(\mathrm{mol} \mathrm{s})$, whereas the constant value from $\mathrm{BP}^{\circ-}$ to $\mathrm{MV}^{2+}$ is $8.0 \times 10^{8} \mathrm{~L} /(\mathrm{mol} \mathrm{s})$, which is one order of magnitude faster than $k_{\text {diff. }}$ The higher rates in ILs may be realized in more organized media, such as IL crystals. A similar phenomenon was observed by photoinduced electron transfer in ionic liquids [18].

\section{Conclusion}

In this study, we used time-resolved pulse radiolysis techniques to measure the rates of intermolecular electrontransfer reactions in $\mathrm{BuPyBF}_{4}$ ionic liquids and conventional solvents. The radiolysis behavior showed that $\mathrm{BuPy}^{+}$cation was easily reduced by solvated electrons and that $\mathrm{BuPy}^{+}$ generated the active radical BuPy', which can follow the electron transfer to various solutes. Several reductions oc- curred with rate constants significantly higher than the diffusion-controlled limit. By contrast, the rate constants for the same reactions in water and $i-\mathrm{PrOH}$ were slower than the diffusion-controlled limit. This fast reaction is interpreted as solvent-mediated mechanism, in which an electron reaches its final destination via intervening pyridinium groups without requiring the diffusion of a specific radical.

This work was supported by the National Natural Science Foundation of China (20973192, 11079007). The authors are grateful to Mr ShanLiang $\mathrm{Lu}$ and TieMing Yu for the technical assistance and encouragement in the pulse radiolysis experiments in Shanghai Institute of Applied Physics, China.

1 Rogers R D, Seddon K R. Ionic liquids-Solvents of the future. Science, 2003, 302: 792-793

2 Earle M J, Esperanc J M S S, Gilea M A, et al. The distillation and volatility of ionic liquids. Nature, 2006, 439: 831-834

3 MacFarlane D R, Seddon K R. Ionic liquids-Progress on the fundamental issues. Aust J Chem, 2007, 60: 3-5

4 Mozumder A. Fundamentals of Radiation Chemistry. San Diego: Academic Press, 1999

5 Grodkowski J, Neta P. Formation and reaction of $\mathrm{Br}_{2}{ }^{--}$radicals in the ionic liquid methyltributylammonium bis(trifluoromethylsulfonyl) imide and in other Solvents. J Phys Chem A, 2002, 106: 11130-11134

6 Behar D, Neta P, Schultheisz C. Reaction kinetics in ionic liquids as studied by pulse radiolysis: Redox reactions in the solvents methyltributylammonium bis(trifluoromethylsulfonyl)imide and $n$-butylpyridinium tetrafluoroborate. J Phys Chem A, 2002, 106: 3139-3147

7 Gardas R L, Costa H F, Freire M G, et al. Densities and derived thermodynamic properties of imidazolium-, pyridinium-, pyrrolidinium-, and piperidinium-based ionic liquids. J Chem Eng Data, 2008, 53: 805-811

8 Bandres I, Giner B, Artigas H, et al. Thermophysical properties of $\mathrm{N}$-octyl-3-methylpyridinium tetrafluoroborate. J Chem Eng Data, 2009, 54: 236-240

9 Bandres I, Giner B, Gascon I, et al. Physicochemical characterization of $n$-butyl-3-methylpyridinium dicyanamide ionic liquid. J Phys Chem B, 2008, 112: 12461-12467

10 Fu H Y, Xing Z G, Wu G Z, et al. Laser photolysis studies of quaternary ammonium ionic liquids aqueous solution. Res Chem Intermed, 2011, 37: 79-89

11 Fu H Y, Xing Z G, Cao X Y, et al. Pulse radiolysis studies of functional substituted imidazolium-based ionic liquids. Chin Sci Bull, 2012, 57: 2752-2758

12 Buxton G V, Stuart C R. Re-evaluation of the thiocyanate dosimeter for pulse radiolysis. J Chem Soc Faraday Trans, 1995, 91: 279-281

13 Buxton G V, Greenstock C L, Helman W P, et al. Critical review of rate constants for reactions of hydrated electrons, hydrogen atoms and hydroxyl radicals $\left(\mathrm{OH} / \mathrm{O}^{-}\right)$in aqueous solution. J Phys Chem Ref Data, 1988, 17: 578-580

14 Ma J H, Lin W Z, Wang W F, et al. Characterization of reactive intermediates in laser photolysis of nucleoside using of sodium salt anthraquinone-2-sulfonic acid as photosensitizer. Radiat Phys Chem, 1999, 54: 491-497

15 Buntinx G, Naskrecki R, Poizat O. Subpicosecond transient absorption analysis of the photophysics of 2,2'-bipyridine and 4,4'-bipyridine in solution. J Phys Chem, 1996, 100: 19380-19388

16 Espenson J H. Chemical Kinetics and Reaction Mechanisms. 2nd ed. New York: McGraw-Hill, 1995. 201-202

17 Skrzypczak A, Neta P. Diffusion-controlled electron-transfer reactions in ionic liquids. J Phys Chem A, 2003, 107: 7800-7803

18 Vieira R C, Falvey D E. Solvent-mediated photoinduced electron transfer in a pyridinium ionic liquid. J Am Chem Soc, 2008, 130: 1552-1553

Open Access This article is distributed under the terms of the Creative Commons Attribution License which permits any use, distribution, and reproduction in any medium, provided the original author(s) and source are credited. 